\title{
GREEN MANAGEMENT SYSTEM
}

\author{
Ali Hasan \\ Dosen Sekolah Tinggi Pariwisata AMPTA Yogyakarta \\ Ali43ibc@gmail.com
}

\begin{abstract}
Green Management System (GMS) is an effort to protect the environment. With the depletion of natural resources, the protection of the environment is not only limited to a small part of its corporate social responsibility, but it must be a model in business organizations. Model GMS-oriented environment, will systematically affect the company in reducing waste, reducing the use of natural resources, reduce pollution and continuously monitoring the purpose of creating business results were positive for all stakeholders.

Modern business travel will continue to come under pressure from the environment and the realization of the company's sustainability strategy, the managers began to review the possibility of implementation of GMS in the management system of the organization; directs the management of the organization, developing technologies to reduce adverse environmental impact and develop the production of green (green production) more rational and cost-effective.

Development and implementation of green policies in environmental management becomes an important part of the transformation of business management functions in optimizing the use of GMS to improve corporate performance and benefits for environmental sustainability.

Direct implications for the development and implementation of environmental protection in the modern business organization in accordance with modern green standards and the principles of environmental sustainability and a company associated with the creation of the organization, program and structure, education and training of human resources will enable the transfer and dissemination of knowledge for environmental protection.
\end{abstract}

Keywords: Green Management Systems, Green Production, Sustainability company and Environment

\section{PENDAHULUAN}

Manajemen sebagai ilmu sangat dinamis, sejak kelahirannya tahun 1840 sampai sekarang paradigmanya terus berubah mengikuti peradaban manusia dan tuntutan lingkungan. Kemunculan paradigma "Go Green" menjadi salah satu driver perjalanan organisasi (komersial - non komersial), Ke depan, perusahaan yang sukses adalah perusahaan yang mampu menghasilkan temuan yang inovatif dan revolusioner dalam menggunakan energi green. ${ }^{1}$ Saat ini, bisnis berada dalam satu jaringan global, berkooperasi mungkin menghasilkan cara yang lebih baik dan kuat dibanding berkompetisi, keputusan berkooperasi atau berkompetisi sangat tergantung pada CEO.

Istilah go green, back to nuture dan sejenisnya menjadi sangat pupuler di kalangan masyarakat, sementara itu dalam dunia bisnis atau organisasi, ada kecenderungan dalam banyak para ilmuan 
manajemen menyebutnya sebagai sistem manajemen green (Green Management System-GMS). Saat ini manajemen green masih dianggap sebagai bagian kecil dari tanggung jawab sosial perusahaan, dalam waktu yang sama, dunia usaha karena berbagai alasan mempengaruhi manusia dan lingkungan. Di sisi lain kita juga tahu bahwa model bisnis inti terus berubah dengan tren globalisasi teknologi, demografi dan faktor-faktor lain akan mempengaruhi struktur dan budaya organisasi.

Dalam kaitan itu berbagai riset dilakukan untuk mengeksplorasi masa depan masyarakat, lingkungan, bisnis dan lingkungan kerja yang secara eksplisit berdampak pada model manajemen dalam mencapai tujuannya. Tantangan yang tidak pernah usang dalam manajemen berkaitan dengan pengetahuan untuk menggabungkan model dengan perubahan lingkungan. Perusahaan mengembangkan kesadaran sosial yang kuat, rasional dan feeling green sebagai bagian dari tanggung jawab perusahaan. Konsumen menuntut etika dan kredensial green sebagai prioritas utama bisnis untuk menyelaraskan agenda mereka. $^{2}$

Manajemen green dikonseptualisasikan sebagai model manajemen yang didesign untuk memenuhi kebutuhan perusahaan masa kini dan akan dihargai jika mampu menciptakan keberlanjutan manfaat lingkungan dan sumberdaya alam dalam memenuhi kebutuhan perusahaan generasi mendatang. ${ }^{3}$ Green activity atau aktivitas ramah lingkungan untuk melestarikan lingkungan dan sumber daya alam adalah inti dari GMS

Memahami arti penting manajemen green dari perspektif perusahaan terkait dengan kebijakan green yang dapat meningkatkan kinerja perusahaan. Pemahaman hubungan manajemen green dan kinerja perusahaan sangat penting dalam rangka mengembangkan kebijakan dan inovasi green teknologi, serta instalasi perusahaan ramah lingkungan yang tidak hanya meningkatkan kinerja perusahaan tetapi sangat bermanfaat bagi lingkungan

\section{LITERATURE REVIEW}

Dalam berbagai kajian akademik dan empiris menyimpulkan bahwa, GMS adalah alat untuk mengelola dampak kegiatan bisnis terhadap lingkungan. GMS mengintegrasikan pengelolaan lingkungan ke dalam operasi perusahaan sehari-hari, perencanaan jangka panjang dan adopsi sistem manajemen mutu lainnya. ${ }^{4}$

\section{Konsensus Literatur}

GMS, sebagai salah satu model manajemen menghendaki penilaian dampak lingkungan, menetapkan target untuk mengurangi dampak tersebut dan merencanakan cara untuk mencapai target. Banyak komponen yang harus dipertimbangkan ketika manajemen memutuskan untuk mengembangkan GMS: Kebijakan lingkungan, identifikasi dampak lingkungan, tujuan dan sasaran, rencana pengelolaan lingkungan, tanggung jawab dan struktur pelaporan, audit sistem perbaikan terusmenerus.

Para ilmuan dan praktisi mengelompokkan dimensi GMS sebagai berikut: operasi green yang efektif, profitability, produk atau jasa yang kompetitif, perluasan pasar, peningkatan citra perusahaan, dan peningkatan manajemen. GMS yang proaktif dan efektif ditunjukkan oleh level (1) tanggung jawab perusahaan atas isu-isu lingkungan, (2) kebijakan lingkungan, (3) strategi yang mencerminkan voice lingkungan, (4) tujuan 
dan sasaran lingkungan yang baik, jelas dan terukur.

Berbagai diskusi mendalam menunjukkan kesepahaman tentang cakupan dimenasi GMS adalah produksi green, pengadaan green, pembelian green, manajemen green, design green, arsitek green, budaya green, produktivitas green dan sebagainya. Konsensus literatur pengelolaan lingkungan internal merupakan kunci untuk meningkatkan kinerja perusahaan dan dukungan manajer senior diperlukan dan sebagai generator utama untuk keberhasilan adopsi dan implementasi GMS yang inovatif, pengembangan teknologi, program dan kegiatan.

\section{Kararkteristik Sistem}

Sebuah sistem terdiri dari set elemen yang saling berinteraksi dalam serangkaian kondisi kolektif yang membatasi pergerakan disebut "lingkungan" yang didefinisikan sebagai satu set elemen bersama-sama dengan hubungan antar objek dan antar atribut (struktural) atau dapat dilihat sebagai seperangkat bagian yang terkoordinasi untuk mencapai satu set tujuan (fungsional) ${ }^{\mathbf{5}}$ Kombinasi dan hubungan struktural dan fungsional inilah yang membuat gagasan sistem itu berguna. Apapun jenis sistem dapat didefinisikan sebagai perubahan semua atribut yang mempengaruhi sistem dan atau atributnya diubah oleh perilaku sistem Ketika tidak ada impor atau ekspor energi, seperti informasi dan lainnya dalam interaksi yang tidak berubah dan tidak tergantung pada perilaku elemen lingkungan. Akibatnya, sumber gangguan sistem bukan berasal dari lingkungan, tetapi dihasilkan oleh system itu sendiri.

GMS merupakan sistem terbuka terhadap perubahan semua atribut misalnya bahan baku, energy, informasi dan ling- kungannya. Misalnya, impor bahan baku bisnis, tenaga kerja dan informasi dirubah menjadi produk dan jasa sebagai output perusahaan untuk pelanggannya. Uang dan pasar menyediakan mekanisme yang memfasilitasi pertukaran tersebut. analisis input/output dapat digunakan untuk memodelkan aliran energi ini. ${ }^{6}$

Banyak sistem menunjukkan kemampuan bereaksi terhadap lingkungan untuk memastikan operasi sistem itu. Adaptasi sistem jenis ini memiliki kemampuan untuk mengubah diri sendiri atau lingkungan ketika system itu merugikan. ${ }^{7}$ Sistem merupakan sarana untuk mencapai tujuan. Tujuan dari sistem mungkin hanya menjadi kelangsungan hidup dan proses-proses yang mendorong perilaku adaptif (mekanisme homeostatis) dan pada tingkat sederhana mekanisme homeostatis ini bergerak menuju produksi steady state (dinamis) yang kemudian dicapai melalui proses negentropic yang mengambil lebih banyak energi untuk sistem. Pada tingkat yang lebih kompleks, proses homeodinamis menjadi salah satu faktor penting dalam melestarikan karakter sistem; misalnya, prestasi pertumbuhan ekonomi.

GMS menunjukkan banyak karakteristik dari mekanisme homeostasis yang kompleks karena membantu bisnis mencapai keseimbangan dinamis dan melestarikan karakter. Misalnya, salah satu fungsi manajemen tradisional adalah untuk mengumpulkan informasi dari dari lingkungan (customers) dan mengirimkannya ke bagian lain di perusahaan. Dalam menjalankan fungsi informasi ini diterjemahkan dan kemudian ditata kembali menurut persepsi GMS dari perspective kebutuhan perusahaan. Decoding atau fase recoding operasi ini sangat penting untuk bagaimana informasi akan digunakan dalam 
mengubah perilaku perusahaan. Jelas ada batas untuk sejauh mana manajemen dapat bertindak dalam mekanisme homeostatis sebagai subsistem internal perusahaan, lingkungannya, jenis dan relasi sistem dengan lingkungan.

\section{Analisis Keberlanjutan Perusahaan}

Berbagai analisis green, berupaya menemukan pendekatan praktis dan menarik dalam meningkatakan produktivitas dan perlindungan lingkungan. Para ilmuan manajemen memperkenalkan konsep green productivity yang didefinisi-kan sebagai strategi untuk meningkatkan produktivitas dan kinerja sosial, budaya, ekonomi, dan lingkungan secara keseluruhan. Aplikasi kebijakan produk-tivitas dan manajemen lingkungan, alat, teknik dan teknologi untuk mengurangi dampak lingkungan dari kegiatan perusahaan. ${ }^{8}$

Berbagai penelitian menggunakan konsep keberlanjutan ekologi sebagai kerangka kerja untuk mempelajari praktek manajemen dalam konteks operasional dan strategi. ${ }^{9}$ Sebagai bagian dari analisis GMS, riset tentang penghijauan rantai pasokan dalam berbagai konteks termasuk desain produk, desain proses, praktek pembelian dan bauran unsur-unsur lainnya secara luas untuk menciptakan paralel peningkatan kualitas total pengelolaan lingkungan. Dalam mengembangkan sistem manajemen green, esensinya adalah: (1) mengurangi sampah dan (2) memaksimalkan efisiensi sumber daya melalui empat konsep kunci yaitu pemberdayaan, pendidikan, efisiensi, excellence. ${ }^{\mathbf{1 0}}$

Kajian lain menunjukkan bahwa kebijakan green merupakan komitmen serius atas nama perusahaan di mana setiap kata dan frasenya akan sangat hati-hati dan implikasinya dapat dipahami dengan menggunakan standar lingkungan. Pem- bentukan dan implementasi GMS berbasis jangka panjang diprogram melibatkan partisipasi karyawan (mitra internal bisis) di semua tingkatan dan semua fungsi secara efektif. Mereka harus melakukan dan mendukung tidak hanya untuk sistem yang efektif, tetapi juga untuk perbaikan berkesinambungan dari factor kunci sukses pelaksanaan atribut: (1) sikap manajemen, commitment dan dukungan top manajemen, (2) struktur perubahan organisasi dan tanggung jawab, (3) aspek sosial dan undang-undang lingkungan, (4) aspek teknis bantuan spesialis lingkungan. ${ }^{11}$

Dalam rangka mempertahankan perbaikan kinerja lingkungan, kesesuaian dan efektivitas GMS, manajemen puncak harus meninjau dan mengevaluasi GMS secara berkala. Review manajemen harus didasarkan pada hasil audit GMS. GMS sebagai sistem manajemen berbasis lingkungan, pengembangan dan implementasi yang efektif pasti dipengaruhi oleh sebagian besar aspek eksternal dan sosial. Ini termasuk undang-undang lingkungan, tekanan pasar, dan hubungan mitra internal bisnis. Kecenderungan meningkatnya tekanan undang-undang lingkungan sebagai harapan masyarakat yang terus meningkat dan dengan peningkatan tekanan untuk kelestarian lingkungan, maka perusahaan diharapkan untuk mengimplementasikan strategi mengurangi dampak lingkungan dari produk dan layanan mereka. Untuk membangun citra lingkungan mereka, perusahaan harus memeriksa kembali tujuan bisnis mereka. Sukses dalam menangani permasalahan lingkungan dapat memberikan peluang baru untuk kompetisi, dan cara-cara baru untuk menambah nilai bisnis inti. ${ }^{12}$

Dalam perusahaan green, perusahaan perlu membentuk tim pemasok untuk meninjau bahan baku dan perlengkapan 
yang berfungsi sebagai input untuk proses produksi dan juga bekerja dengan pemasok untuk menyelesaikan setiap masalah kualitas produk dan lingkungan. Mengadakan lokakarya, pendidikan dan pelatihan untuk mengembangkan pengetahuan dan keahlian mitra internal bisnis untuk mengerjakan dan mengevaluasi kinerja layanan, kemampuan teknis, kualitas, biaya, fleksibilitas dan kinerja lingkungan secara keseluruhan. Dalam cara yang sama, manajemen menyadari peran para mitra internal bisnis dalam menerapkan prosedur ramah lingkungan kedalam greem production dan memastikan bahwa:

1. Produk/jasa yang dihasilkan oleh perusahaan ramah lingkungan alam;

2. Pencegahan pencemaran sumber daya dalam proses produksi;

3. Praktek cleaner produksi diikuti dengan penggunaan teknologi ramah lingkungan;

4. Closed loop manufactured dimasukkan semaksimal mungkin, sehingga limbah yang dihasilkan diolah dan didaur ulang kembali ke produksi;

5. Malakukan re-use dan daur ulang bahan;

6. Penggunaan Bahan berkurang;

7. Peningkatan konten daur ulang dalam produk adalah;

8. Proses dioptimalkan sehingga limbah berbahaya dapat diminimalkan; dan

9. Produk didesain ulang (desain untuk lingkungan) sehingga dampak yang merugikan lingkungan dari produk dapat diminimalkan. ${ }^{13}$

Analisis keberlanjutan perusahaan dalam perspektif GMS mencakup (1) keberlanjutan konsumsi energi, dan instalasi pabrikasi; (2) harapan dan suara masyarakat dan pelanggan (expectation and voice of customer, and sociaty); dan (3) mengurangi biaya dan limbah dalam pendekatan produktivitas. Sejumlah cara untuk mengukur kinerja lingkungan, sasaran, dan memastikan data yang lebih baik untuk membuat keputusan serta menyediakan informasi kepada regulator dan semua pemangku kepentingan utama. Model rinci terdiri dari tujuh langkah efektif dalam penilaian kinerja lingkungan: (1) pilih cara yang paling tepat; (2) set target; (3) identifikasi dan laksanakan langkah-langkah potensial; (4) tentukan konteks lingkungan dan tujuan; (5) memantau dan komunikasikan hasilnya, (6) hasil; (7) ulasan manajerial.

\section{Perusahaan dan Lingkungan}

Model GMS memerlukan keterlibatan lintas bidang ilmu, teori, inovasi, nilai-nilai dan tren budaya yang mengikuti prinsipprinsip dasar dalam pembentukan green bisnis. ${ }^{14}$ Dari sudut perusahaan, GMS berkaitan dengan :

1. masalah lingkungan, ekonomi, sosial, dan budaya organisasi merupakan tema penting dalam mempertajam fokus manajemen berbasis lingkungan (green management)

2. pola-pola baru dan tren, reformasi struktural dan partisipasi perusahaan yang lebih luas

Tujuan dasar desain ulang model manajemen perusahaan untuk memungkinkan menjadi lebih efisien dan lebih baik dalam menangani isu-isu kritis perusahaan green. Transformasi radikal sebagai konsekuensi dari proses globalisasi dan permintaan pasar yang berkembang untuk produk green dan produk yang tidak memiliki efek samping terhadap lingkungan. Perusahaan green adalah perusahaan yang memproduksi barang atau jasa yang 
berkontribusi langsung terhadap upaya melestarikan atau meningkatkan kualitas lingkungan dan meningkatkan penggunaan sumber daya. Dalam hal produksi green, fokus manajemen pada pencegahan atau menghindari masalah greenwash, mencegah emisi pada sumberdaya dan perbaikan terus-menerus untuk meningkatkan kinerja perusahaan green. ${ }^{15}$

Tujuan perusahaan green meliputi tiga bidang utama (1) minimalisasi emisi, dan limbah, (2) minimalisasi penggunaan sumber daya yang langka dan bentuk energi terbarukan dan (3) minimalisasi siklus hidup biaya produk atau jasa. Memperkenalkan konsep perusahaan green tidak hanya berlaku untuk kegiatan produksi tetapi juga untuk domain kegiatan dan layanan. Kegiatan green atau layanan adalah salah satu yang dapat menghasilkan energi terbarukan (termasuk energi alternatif seperti angin, matahari, air, biogreen, dll); mendaur ulang bahan yang ada; memproduksi, membangun, memasang atau merawat produk dengan jumlah konsumsi energy seminimal mungkin; menyediakan dan melakukan pelatihan yang sesuai; mempromosikan dan meningkatkan kesadaran untuk menghasilkan produk alami.

Melalui kontrol green, efek organisasi bisa dicapai, kualitas produk yang lebih tinggi bersamaan dengan penurunan biaya operasi, waktu, energi dan material yang digunakan. Banyak perusahaan mengakui strategi bisnis green sebagai faktor kunci untuk keunggulan kompetitif dan efisiensi bisnis dalam dekade mendatang. Seperti disebutkan sebelumnya, isu green menjadi penting sebagai akibat dari meningkatnya tuntutan dan kesadaran ekologis konsumen tentang bagaimana produk mempengaruhi lingkungan. Ini berarti bahwa di samping keuntungan sebagai tujuan utama dari sebuah bisnis, proses peningkatan kualitas green menjadi sama pentingnya, ${ }^{\mathbf{1 6}}$ dan perusahaan menyadari bahwa green production membawa manfaat berikut:

1. Penurunan kewajiban jangka panjang; kewajiban jangka panjang adalah kewajiban hukum dari organisasi untuk melakukan pemurnian udara yang terkontaminasi, tanah dan air akibat dari zat berbahaya. Dengan penerapan teknologi green yang tidak menghasilkan polusi dan limbah, maka tidak ada kebutuhan untuk melakukan tindakan perbaikan.

2. Pengurangan biaya yang ditetapkan oleh hukum; karena produksi green yang memang menghindari zat berbahaya, maka organisasi tidak perlu meminta izin khusus; mengolah limbah, menggunakan teknik kontrol khusus dan monitoring atau memberikan laporan yang diperlukan;

3. Pengurangan risiko dalam rantai pasokan; program aksi bisnis green mengelola rantai pasokan dengan cara yang lebih baik untuk mencegah warisan risiko yang disebabkan oleh pemasok;

4. Peningkatan efisiensi internal; organisasi memiliki keuntungan finansial dari produksi green karena mengurangi biaya operasional. Proses kegiatan bisnis berorientasi green, zat berbahaya diganti dengan yang tidak berbahaya, bahan beracun dilarang untuk diproduksi, mencegah polusi dan limbah dipatikan akan mengurangi biaya produksi;

5. Meningkatkan peluang pasar; karena meningkatnya permintaan untuk produk green, perusahaan dapat memperluas pasar mereka. 
Peluang green bisnis dan kesadaran dampak lingkungan, identifikasi dampak aktivitas bisnis, kebijakan untuk mengurangi atau menghilangkan dampak negatif; dan menentukan tanggung jawab masingmasing mitra internal perusahaan dalam perlindungan lingkungan yang optimal dapat dicapai dengan pendidikan dan pelatihan mitra internal bisnis yang relevan dengan tujuan ini. ${ }^{\mathbf{1 7}}$

\section{Power Lingkungan}

GMS sebagai sistem terbuka berinteraksi dengan lingkungan, memerlukan pemahaman komprehensif tentang perusahaan dan perilaku manajemen terhadap setiap elemen seperti dalam tabel 1. ${ }^{\mathbf{1 8}}$ Hubungan pertukaran sosial yang dipertahankan dari

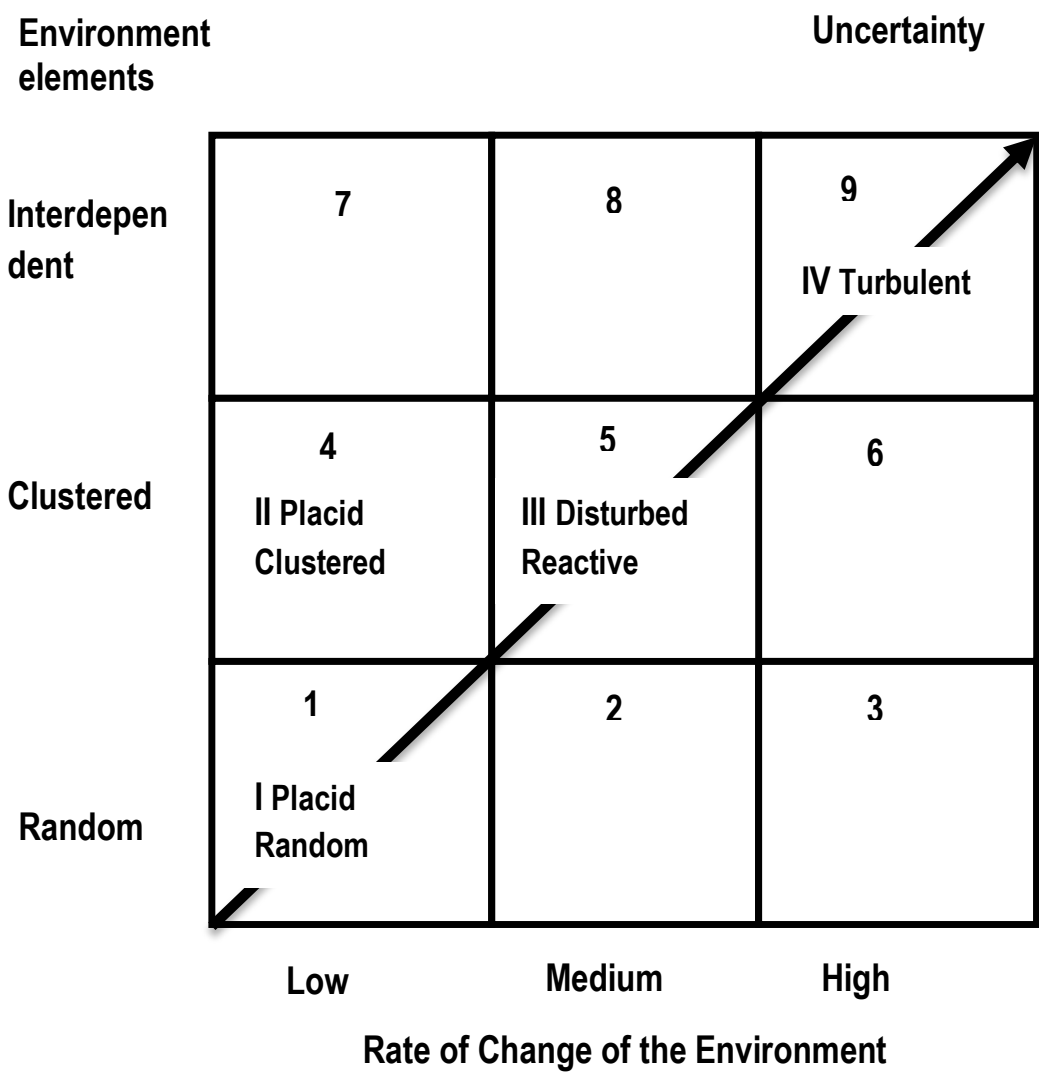

Gambar 1. Power Lingkungan

Gambar 1 menunjukkan ketergantung lingkungan, dan (b) berbagai tingkat perusahaan dengan lingkungan dalam perubahan dari waktu ke waktu. Setiap berbagai tingkat kompleksitas. Setiap elemen memiliki atribut positif (mewakili tingkat kompleksitas lingkungan bergan- tujuan) atau atribut negative (hal-hal yang tung pada (a) differensiasi organisasi dalam waktu ke waktu menentukan berbagai tingkat hierarchy sistem. Misalnya, dalam hal tujuan, satu peran manajemen adalah untuk memastikan bahwa subsistem dikoordinasikan dengan subsistem fungsional lainnya. fungsi sistem control ini dapat dicapai melalui serangkaian pertukaran umum. pola stabil dari pertukaran ini mendefinisikan apa yang dikenal sebagai struktur organisasi perusahaan (L11). sistem yang stabil dan hubungan pertukaran lingkungan akan menentukan struktur industry. Model ekonomi, organisasi industri, dan strategi bersaing telah dikembangkan untuk membantu memahami dampak dari hubungan ini pada suatu perusahaan. $^{19}$ 
harus dihindari) dari taksonomi dan kompleksitas lingkungan.

Tabel 1. Interaksi Elemen Lingkungan dengan Perusahaan

\begin{tabular}{|c|c|c|}
\hline $\mathrm{L}_{11}$ & \multicolumn{2}{|c|}{$\mathrm{L}_{1 \rightarrow 2}$} \\
\hline $\mathrm{L}_{22}$ & \multicolumn{2}{|c|}{$\mathrm{L}_{\rightarrow 2}^{2}$} \\
\hline di mana & & \\
\hline $\mathrm{L}$ & : & menunjukkan potensi hu-bungan; \\
\hline 1 & : & mengacu pada perusahaan, \\
\hline 2 & : & mengacu pada lingkungan. \\
\hline $\mathrm{L}_{11}$ & : & mengacu proses dalam peru-sahaan; misalnya, hirarkhis struktur \\
\hline $\mathrm{L}_{22}$ & : & $\begin{array}{l}\text { saling ketergantungan dalam lingkungan itu sendiri (sebab akibat tekstur); } \\
\text { misalnya, dis-tribusi ke pelanggan potential; }\end{array}$ \\
\hline $\mathrm{L} 1 \rightarrow 2$ & : & $\begin{array}{l}\text { pertukaran antara enterprise dan lingkungan yang consu-mated menurut } \\
\text { perspective perusahaan; misalnya, strategi penjualan; }\end{array}$ \\
\hline $\mathrm{L} 2 \rightarrow 2$ & : & $\begin{array}{l}\text { pertukaran antara enterprise dan lingkungan yang consu-mated menurut } \\
\text { perspective lingkungan; misalnya, strategi regulasi untuk menangkal } \\
\text { pengaruh enterprise. }\end{array}$ \\
\hline
\end{tabular}

1. Placid Randomized Environment Tujuan dan hal-hal yang relatif tidak berubah dan didistribusikan secara acak melalui waktu dan ruang. Untuk bertahan hidup, sistem dalam lingkungan harus bereaksi dengan cara predeter-mined terhadap sasaran ditemui. Pola reaksi ini error dan hanya untuk jenis tertentu dari lingkungan. Tidak ada perbedaan antara strategi dan taktik optimal, taktik sederhana cukup untuk melakukan yang terbaik pada level local. ${ }^{\mathbf{2 0}}$.

2. Placid Clustered Environment

Beberapa textur lingkungan misalnya tujuan dan noxiants (hal-hal yang merugikan) tidak berinteraksi dengan cluster lingkungan. Strategi dapat dirumuskan untuk mengarahkan sistem dalam mencari kelompok sasaran dan menghindari kelompok yang merugikan. Untuk mencapai tujuan perusahaan dibutuhkan konsentrasi sumber daya dan kepatuhan terhadap rencana. Kelangsungan hi- dup perusahaan terkait dengan pengetahuan tentang varian lingkungan. Perusahaan yang beroperasi dalam clustered environment, perkembangan dan perubahan lingkungan akan menjadi fungsi produksi, efisiensi distribusi, dan kemampuan perusahaan untuk memperluas pasar.

3. Disturbed Reactive Environment Satu sistem dari jenis yang sama (misalnya, dua perusahaan/produsen untuk produk serupa) bergantung pada lingkungan untuk kelangsungan hidup mereka. Gagasan pangsa pasar menjadi penting dan perusahaan perlu menggunakan strategi, taktik dan operasi untuk bertahan hidup dan berkembang. Tujuan perusahaan didefinisikan dalam kekuasaan dan kemampuan untuk mencapai tujuan. Masing-masing perusahaan tidak hanya harus mempertimbangkan pesaingnya, tetapi harus tahu bagian dari lingkungan mana pesaing itu 
bergerak sesuai dengan dinamisasi lingkungan.

4. Turbulent Environment

Ini adalah jenis lingkungan yang dinamis karena sumber varians yang timbul tidak hanya dari sistem dan hubungan antara tujuan dengan fluktuasi lingkungan itu sendiri. Ketika konsumen dan lingkungan bergejolak, maka ada peningkatan energy untuk penelitian dan prediksi untuk mengembangkan kapasitas dalam memenuhi tantangan kompetitif dan mengatasi jenis turbulensi lingkungan. Bentuk kompleksitas lingkungan melibatkan peningkatan yang signifikan dalam ketidakpastian masa depan.

Level kompleksitas lingkungan tidak diskrit, mereka membentuk "tipe ideal" dimana lingkungan dapat diklasifikasikan. Lingkungan tipe IV dimana tingkat ketidakpastian dan perubahan potensial meningkat. Dalam konteks bisnis kontemporer, bentuk ekstrim lingkungan (randomize lingkungan dan turbulensi lingkungan) yang dialami oleh perusahaan, dalam essence teoretikal, perusahaan dapat hidup berdampingan untuk tujuan yang sama atau berbeda akan mengalami derajat pengaruh yang berbeda dari masing-masing tipe lingkungan.

Konsep ketidakpasstian lingkungan menjadi relevan untuk system bergantung pada besarnya efek ketidakpastian ini. Unsur lingkungan dapat dipartisi sesuai dengan tingkat pengaruhnya terhadap sistem. Elemen lingkungan dapat menyebabkan sistem untuk mengubah baik struktur dan perilaku dari waktu ke waktu. Misalnya, perubahan produk pemasok dapat menyebabkan perusahaan memodifikasi proses produksi dan sebagainya.

Konsep "ketidakpastian yang relevan" berasal fungsi organisasi dan laju perubahan lingkungan. Akibatnya, ketidakpastian yang relevan menghadapi fungsi ketidakpastian lingkungan dan jenis hubungan sistem dengan lingkungan.

Tabel 2 menunjukkan empat jenis kompleksitas lingkungan, tingkat ketidakpastian yang relevan dengan sistem, pola reaksi normatif, dan berbagai filosofi manajemen. Secara struktural, manajemen merupakan sistem terbuka. Perusahaan mengandung unsur-unsur dalam perusahaan itu sendiri (misalnya, kebijakan internal) serta lingkungan dari perusahaan secara keseluruhan. Salah satu fungsi utama manajemen adalah mekanisme homeodinamis membantu perusahaan mempertahankan karakter dan mencapai keseimbangan yang lebih dinamis.

Tabel 3 menunjukkan bahwa proses manajemen tergantung pada karakter ekonomi. Kondisi ekonomi merupakan salah satu sumber penting dari ketidak-pastian yang relevan dalam sistem manajemen bisnis.

\section{GMS Strategic}

Strategi adalah alat yang berguna dalam membantu organisasi dalam mendefinisikan tanggung jawab yang sesuai dengan manajemen green. Model GMS merupakan bagian integral dari model operasi manajemen, oleh karena itu penetapan indikator positif dari berbagai aktivitas bisnis terhadap perlindungan lingkungan menjadi sangat penting, yang kemudian digunakan dalam memeriksa realisasi tujuan, termasuk mendorong semua pemasok untuk memenuhi tujuan kebijakan green. 
Tabel 2 : Hubungan GMS dengan Lingkungan ${ }^{21}$

\begin{tabular}{|l|l|l|l|l|}
\hline Type & \multicolumn{1}{|c|}{ Environment } & $\begin{array}{l}\text { Relevant } \\
\text { Uncertainty }\end{array}$ & $\begin{array}{c}\text { The Normative Response of the } \\
\text { System }\end{array}$ & Management Philosophies \\
\hline I & Placid Random & Low & Automate Reaction & The Mathematical Model \\
\hline II & Placid Clustered & Low/Medium & Strategy & The Empirical Science \\
\hline III & $\begin{array}{l}\text { Disturbed } \\
\text { Reactive }\end{array}$ & Medium/High & Strategy, Tactics and Operations & The Decision Theory \\
\hline IV & $\begin{array}{l}\text { Turbulent } \\
\text { High }\end{array}$ & Initiate System Change & The Management \\
Process
\end{tabular}

Tabel 3 : Manajemen dan Perkembangan Ekonomi ${ }^{22}$

\begin{tabular}{|c|c|c|c|c|c|c|}
\hline $\begin{array}{c}\text { Degree of } \\
\text { Environmental } \\
\text { Influence }\end{array}$ & $\begin{array}{l}\text { Environment } \\
\text { Connection }\end{array}$ & $\begin{array}{c}\text { Stages of } \\
\text { Economic } \\
\text { Development }^{\mathrm{a}}\end{array}$ & $\begin{array}{c}\text { Type } \\
\text { of } \\
\text { System }\end{array}$ & $\begin{array}{c}\text { Typical } \\
\text { Environment }\end{array}$ & $\begin{array}{l}\text { Goal of the } \\
\text { Enterprise } \\
\text { Success }\end{array}$ & $\begin{array}{c}\text { Management } \\
\text { Processes }\end{array}$ \\
\hline \multirow[b]{3}{*}{ Low } & \multirow[b]{3}{*}{$\mathrm{L}_{11,} \mathrm{~L}_{1}$ à, $\mathrm{L}_{2}$ à } & $\begin{array}{l}\text { Economic Self- } \\
\text { sufficiency }\end{array}$ & Closed & & & no exchanges \\
\hline & & $\begin{array}{l}\text { Primitive } \\
\text { Communalism }\end{array}$ & Closed & & & no exchanges \\
\hline & & Simple Barter & Open & I & Volume & $\begin{array}{l}\text { Search, } \\
\text { negotiation \& } \\
\text { exchange of } \\
\text { surplus } \\
\text { production }\end{array}$ \\
\hline \multirow[t]{2}{*}{ Low/Medium } & \multirow[t]{2}{*}{$\begin{array}{l}\mathrm{L}_{11,} \mathrm{~L}_{1} \rightarrow 2, \mathrm{~L}_{2} \\
\rightarrow^{1}\end{array}$} & Local Markets & Open & II & $\begin{array}{l}\text { Quality } \\
\text { Products }\end{array}$ & $\begin{array}{l}\text { Exchange of } \\
\text { economic goods } \\
\& \text { a set of } \\
\text { specialized } \\
\text { institutions to } \\
\text { facilitate } \\
\text { exchanges }\end{array}$ \\
\hline & & $\begin{array}{l}\text { Money } \\
\text { Economy }\end{array}$ & Open & II & $\begin{array}{l}\text { Quality } \\
\text { Products }\end{array}$ & $\begin{array}{l}\text { Development of a } \\
\text { common medium } \\
\text { of exchange }\end{array}$ \\
\hline \multirow[b]{2}{*}{ Medium/High } & \multirow[b]{2}{*}{$\begin{array}{l}\mathrm{L}_{11}, \mathrm{~L}_{1} \text { à } 2, \mathrm{~L}_{2} \\
\text { à1, } \mathrm{L}_{22}\end{array}$} & $\begin{array}{l}\text { Early } \\
\text { Capitalism }\end{array}$ & Open & II \& III & $\begin{array}{l}\text { Long-run } \\
\text { Customer } \\
\text { Satisfaction }\end{array}$ & $\begin{array}{l}\text { Activities } \\
\text { developed to } \\
\text { search for groups } \\
\text { of customers, } \\
\text { distribute goods } \\
\& \text { negotiate } \\
\text { exchanges }\end{array}$ \\
\hline & & $\begin{array}{l}\text { Mass } \\
\text { Production }\end{array}$ & Open & II \& III & $\begin{array}{l}\text { Long-run } \\
\text { Customer } \\
\text { Satisfaction }\end{array}$ & $\begin{array}{l}\text { Activities } \\
\text { developed to } \\
\text { improve \& } \\
\text { stimulate the flow } \\
\text { of goods \& } \\
\text { services from } \\
\text { producers to } \\
\text { consumers }\end{array}$ \\
\hline High & $\begin{array}{l}\mathrm{L}_{11}, \mathrm{~L}_{1 \mathrm{à} 2}, \mathrm{~L}_{2} \text { à } \\
{ }_{1} \mathrm{~L}_{22}\end{array}$ & $\begin{array}{l}\text { Affluent } \\
\text { Society }\end{array}$ & Open & III \& IV & $\begin{array}{l}\text { Long-run } \\
\text { Customer } \\
\text { Satisfaction } \\
\text { and Public } \\
\text { Welfare }\end{array}$ & $\begin{array}{l}\text { Probe wants as } \\
\text { opposed to needs } \\
\text { \& adjust products } \\
\text { to meet } \\
\text { interpreted wants }\end{array}$ \\
\hline
\end{tabular}

Strategi manajemen green diperlukan untuk menentukan penggunaan sumber harus mencakup seluruh siklus hidup produk, mulai dari ekstraksi bahan baku daya dalam organisasi dengan cara yang yang diperlukan untuk produksi, paling efisien dan greenly. Strategi ini penanganan limbah sudah dilakukan. 
Instrumen dan reformasi ekologis dalam perekonomian akan memungkinkan tujuan bisnis green lebih mudah dicapai.

Konsep GMS mengkonfirmasi 95\% saving sumberdaya berikut sebagai faktor dasar harus dipertimbangkan dalam model GMS. ${ }^{23}$

1. budaya green dan berpikir green

2. analitis penggunaan energi dan green teknologi

3. penggunaan pembuangan, daur ulang dan perbaikan sistem

4. menentukan kriteria green yang tepat dalam mengembangkan dan memelihara infrastruktur dan utilitas sistem operasi

5. menentukan kriteria green, keselamatan, kualitas dan sistem kerja

6. analisis keausan mesin produksi, depresiasi dan konsumsi energi

Strategi menjadi faktor penting yang memungkinkan perusahaan untuk bertahan hidup dan bergerak menuju pencapaian tujuan yang lebih tinggi. pertimbangan strategis dalam sistem manajemen terkait struktur industry dan posisi pasar menjadi sangat penting. Faktor-faktor strategis dianggap tepat dalam jenis lingkungan ini adalah daya tawar pelanggan dan pemasok, ancaman pesaing baru dan produk pengganti, persaingan antara perusahaanperusahaan yang ada. peramalan teknologi, penelitian dan pengembangan, riset pasar, model perilaku konsumen, dan persaingan antar perusahaan menjadi pertimbangan penting dalam mencapai fungsi produksi yang lebih efisien.

Jika perusahaan memilih GMS diintegrasikan ke dalam model atau sistem manajemen yang sudah ada, dan untuk memastikan keberhasilan perusahaan, manajemen perlu melakukan tinjauan dan mengevaluasi tujuan bisnisnya. Sebuah proses formal dilakukan untuk merencanakan item tindakan tertentu, memantau tindakan untuk memastikan bahwa implementasi GMS itu efektif dan efisien. Jika keputusan memilih GMS diterapkan dalam model manajemen bisnis, strategi berikut dapat digunakan.

1. Membangun dan menetapkan indikator kesehatan perusahaan - bisnis sebagai bahan evaluasi kesehatan bisnis.

2. Mengembangkan bentuk pertemuan di mana manajemen mengulas tujuan utama dari bisnis, misalnya produksi, penjualan, profitabilitas, dan semua indikator lainya yang berkaitan dengan kesehatan bisnis.

3. Mengembangkan frekuensi yang tepat. Frekuensi ulasan manajemen misalnya bulanan (baru) dan kuartalan (maturity) untuk memastikan kesehatan lanjutan dari bisnis.

4. Mengembangkan agenda yang sesuai untuk review. Tinjauan mencakup semua metrik kegiatan yang menyediakan informasi yang baik di mana bisnis membutuhkan perhatian manajemen.

5. Mengintegrasikan ulasan manajemen agar tim manajemen dapat sepenuhnya mengevaluasi kelayakan dan kesehatan perusahaan dengan meninjau semua data yang dapat mempengaruhi kesuksesan perusahaan.

Proses pengendalian operasional dalam perusahaan dapat menyebabkan kebingungan dan konflik di kalangan mitra internal bisnis. Banyak organisasi memiliki instruksi kerja yang terpisah, misalnya, untuk kualitas, keamanan dan isu green. Oleh karena itu sebelum integrasi, lakukan hal-hal berikut ini : 
1. Mengidentifikasi kegiatan-kegiatan produksi yang dapat berdampak pada kualitas kinerja perusahaan (green).

2. Dengan bantuan personil operasi, kembangkan dan sediakan dokumen prosedur, instruksi kerja dan kriteria untuk menghasilkan produk berkualitas, aman dan meminimalkan dampak lingkungan.

3. Mengidentifikasi kegiatan-kegiatan produksi yang dapat berdampak pada kualitas kinerja perusahaan (green).

4. Dengan bantuan personil operasi, kembangkan dan sediakan dokumen prosedur, instruksi kerja dan kriteria untuk menghasilkan produk berkualitas, aman dan meminimalkan dampak lingkungan.

5. Mengembangkan kontrol proses untuk memastikan bahwa bahan ba$\mathrm{ku}$, proses penyelesaian produk akhir diidentifikasi dengan jelas.

6. Mengembangkan proses kontrol penanganan, penyimpanan, pengemasan, dan pengiriman produk.

7. Perusahaan yang telah terintegrasi, proses pengendalian operasional harus menemukan dukungan besar dari mitra internal bisnis, agar bisnis bervisi lingkungan dapat dijalankan dengan baik.

\section{Proses Kerja Green Management System}

Ending dari pembentukan model perlindungan lingkungan adalah meningkatkan kinerja perusahaan berbasis lingkungan. Manfaat utama dari penerapan model manajemen green adalah pembentukan tanggung jawab lingkungan; pengurangan risiko; penghematan biaya dan peningkatan profitabilitas; lebih efisien dalam penggunaan bahan baku dan energy, serta transparansi perlindungan lingkungan.
Dengan demikian akan meningkatkan citra sebagai perusahaan yang peduli terhadap masa depan lingkungan dan sumberdaya alam.

Model GMS merupakan pendekatan yang komprehensif untuk pelaksanaan dan pengembangan perlindungan lingkungan dan memungkinkan peningkatan kesadaran perusahaan akan pentingnya dan perlunya model manajemen green model. Penerapannya meningkatkan kinerja, ${ }^{\mathbf{2 4}}$ karena didukung dengan langkah-langkah operasional yang lebih praktis dalam pekerjaan sehari-hari dalam pengurangan risiko, penghematan biaya dan peningkatan kinerja manajemen secara keseluruhan. Faktor penentu keberhasilan adalah: pendekatan manajemen, perubahan organisasi, aspek teknis dan aspek sosial.

Manajemen puncak mungkin sulit mengenali manfaat tangible dan intangible dalam implementasi model manajemen green, preferensi program green, kegiatan unit bisnis dan fasilitas yang diperlukan dalam mengintegrasikan kegiatan manajemen green dengan inti proses bisnis. ${ }^{25}$ Ketika perusahaan sudah menetapkan tujuan untuk mewujudkan program dan kegiatan green, perusahan perlu melakukan investasi perubahan teknologi untuk mencapai tujuan yang ditetapkan, dan banyak perusahaan gagal menyadari manfaat jangka panjang dari investasi ini

Aspek sosial pelaksanaan dan penerapan GMS menjadi salah satu faktor penting. Mitra internal bisnis dapat merespon dengan perlawanan, kemarahan, frustrasi, kebingungan, takut risiko, takut menjadi inovatif, takut untuk mencoba halhal baru dan beberapa akan menentang tanggung jawab ini. Di sisi lain, manfaat produksi dengan menggunakan GMS menjadi faktor motivasi, terutama karena 
tekanan interlaced dengan tuntutan dematerialisasi. ${ }^{26}$

GMS dapat memperkuat tindakan manajerial dalam membangun keberlanjutan perusahaan, meningkatkan kesadaran dan implementasi program pendidikan - pelatihan mitra internal bisnis berkaitan dengan perlindungan lingkungan. Oleh karena itu manajemen green harus dilihat sebagai kaitan langsung dengan pemahaman dan partisipasi mitra internal bisnis (SDM).

Kecepatan dan ketepatan strategi, perusahaan harus mulai dari pemahaman manajemen green sehingga memungkinkan transformasi produksi tradisional menjadi green production. Partisipasi mitra internal bisnis di semua tingkatan dalam menjaga model manajemen green membuka jalurjalur penting untuk masuk menjadi green bisnis, membantu pengembangan budaya organisasi dan partisipasi mitra internal bisnis dalam memecahkan masalah green business dan keberlanjutannya dalam konteks lingkungan. ${ }^{27}$

Ada empat alasan mengapa perusahaan menggunakan manajemen green. Pertama, konsep pemahaman green dalam mengem-bangkan struktur dan model yang jauh lebih mudah beradaptasi dengan perubahan lingkungan. Kedua, perubahan lingkungan meningkatkan risiko keselamatan dan ketidakpastian usaha, memaksa perusahaan untuk memahami bagaimana melakukan sesuatu yang berbeda. Ketiga, pemahaman nilai, manajemen sangat dinamis dan perubahan yang terus menerus untuk menghasilkan kesepakatan yang lebih baik terhadap perbaikan risiko, keamanan dan peluang yang dihasilkan oleh lingkungan bisnis, dan keempat, perkembangan pengetahuan dan persaingan bisnis, tekanan konsumen dan peraturan mendorong manajemen untuk bertindak sesuai dengan standar perlindungan lingkungan dan prinsip-prinsip keberlanjutan perusahaan ${ }^{28}$ melalui proses tertentu seperti gambar 2 . 


\begin{tabular}{|c|c|c|}
\hline INPUT & $\begin{array}{l}\text { PENGELOLAAN } \\
\text { OPERASIONAL }\end{array}$ & OUTPUT \\
\hline $\begin{array}{l}\text { 1. Bahan baku: } \\
\text { 2. Konsumsi energi: } \\
\text { 3. Informasi dan data } \\
\text { 4. Tenaga kerja:; } \\
\text { 5. Mesin } \\
\text { 6. Peralatan }\end{array}$ & $\begin{aligned} & \text { 1. } \text { Perancangan dan } \\
& \text { penanganan bahan baku } \\
& \text { 2. Keamanan dan } \\
& \text { keselamatan kerja; } \\
& \text { 3. Ketepatan teknik dan } \\
& \text { koordinasi kerja } \\
& \text { 4. Pemanfaatan kapasitas } \\
& \text { mesin dan fasilitas }\end{aligned}$ & $\begin{array}{l}\text { Produk Ramah } \\
\text { Lingkungan }\end{array}$ \\
\hline
\end{tabular}

Pengaruh Variabel lainnya : Budaya, Sistem Nilai dan Norma Perilaku, Teknologi, Pengetahuan, dan Peraturan/Perundang-undangan tentang Lingkungan

Gambar 2. Green Management Process

\section{KESIMPULAN}

Konsep perusahaan green dan kebutuhan perusahaan modern sesuai dengan prinsip-prinsip keberlanjutan terus berkembang sebagai hasil dari pengembangan teknis, teknologi dan industri yang pesat, di samping berbagai keuntungan, juga membawa pertanyaan tentang keselamatan lingkungan dan kelangsungan hidup generasi mendatang. Filosofi GMS dalam program adalah mencegah jauh lebih daripada mengobati, yaitu mencegah efek berbahaya mulai dari awal siklus hidup produk sehingga tidak perlu lagi energi untuk mengolah limbah, proses inilah yang akan membuat keseimbangan antara aktivitas ekonomi dan perlindungan lingkungan, asalkan dalam jangka panjang cleaner produksi dan efisiensi perlindungan lingkungan menjadi norma perilaku.

Minat perusahaan berbasis lingkungan akan terus meningkat. Pemilihan dan penerapan model green yang paling cocok sangat tergantung tidak hanya pada teknologi tetapi juga pada serangkaian kondisi sosial-ekonomi, lingkungan, dan politik. Selain itu, model bisnis ini juga secara signifikan interlaced dengan berbagai jenis pengguna akhir. Ini berarti bahwa aplikasi bisnis ini harus dirancang untuk memastikan bahwa berbagai kebutuhan terpenuhi, misalnya:

1. Memuaskan tuntutan stakeholder,

2. Investasi awal, biaya operasional dan profitabilitas,

3. Pemanfaatan sumber daya secara efektif, mempromosikan dematerialisasi, dll.

Untuk mencapai visi keberlanjutan lingkungan dan sumberdaya alam, pemerintah memiliki kewajiban untuk mempromosikan dan merangsang kemungkinan penggunaan model bisnis, menyusun ulang sektor produksi dan mendorong $\mathrm{R}$ \& D untuk kepentingan komersialisasi dan lingkungan. Peran regulasi Pemerintah sangat diperlukan agar model bisnis ini dapat diterima oleh masyarakat bisnis secara luas. Regulasi green itu wajib, komando dan kontrol regulasi harus 
dilengkapi dengan langkah-langkah penggunaan mekanisme control yang menciptakan efek positif terhadap tindakan manajemen green dalam siklus hidup produk atau proses inovasi masa depan.

Dalam konteks perusahaan dan sesuai dengan kebutuhan akan keberlanjutan lingkungan melibatkan penerapan strategi bisnis dan kegiatan yang memenuhi kebutuhan aktual perusahaan dan stakeholder mereka, sambil terus melindungi, memelihara, dan meningkatkan sumber daya manusia dan alam yang akan dibutuhkan di masa depan

Greenly, adalah alat utama untuk mencapai tujuan ini, GMS merupakan pendekatan yang komprehensif dalam pengembangan model perlindungan lingkungan, pendidikan, dan pelatihan mitra internal bisnis akan memungkinkan perbaikan secara berkesinambungan dari kesadaran perusahaan tentang pentingnya perlindungan lingkungan. Penerapannya meningkatkan kinerja perlindungan lingkungan, tidak hanya dalam hal investasi, tetapi juga dengan meningkatkan langkahlangkah praktis operasional dalam pekerjaan sehari-hari.

\section{REFERENSI}

1. Balazs Vaszkun. $50+50$ Years of Management Around the World: Competition and Cooperation in Hungary, in Japan and in the United States. Corvinus University of Budapest, Hungary. 50th Congress of the Business History Society of Japan

2. Sawant, S. U, et al. 2013. Strategy for Implementation of Green Management System to Achieve Sustainable Improvement for Eco friendly Environment, International Journal of Innovative Research
Science, Engineering and Technology. 2, 10/10.pp 5698 - 5701

3. Polonsky, M. J. 2011. Transformative green: a strategic approach and opportunities. Journal of Business Research, 64/12, 1311-1319.

4. Weis, G., Wodak, R. 2003. Critical Discourse Analysis - Theory and Interdisciplinarity, Palgrave Mac millan Ltd, pp. 1-6, ISBN 0-33397023-3.

5. Churchman, C. W. 1968. The Systems Approach, New York: Dell.

6. Layton, R. A. 1981, "Trade Flows in Macromarketing Systems: Parts I and II," Journal of Macromarketing, 1 \& 2, 35-48, 48-55.

7. Ackoff, R. L. 1971. "Towards a System of Systems Concepts," Management Science, 17/7. 661-671.

8. Chavan. M. 2005. An appraisal of environment management systems. Management of environmental quality, 16/5: 444-463.

9. Sroufe. R. 2006. A framework for strategic environmental sourcing. Greening the Supply Chain.London: Springer. pp 3-23

10. Hall. J. 2001. Environmental supplychain innovation. Greener Management International, 35: 105-119.

11. Zsidisin, G. Siferd. S. 2001. Environmental purchasing: A framework for theory development. European Journal of Purchasing \& Supplying Management, 7: 1-13.

12. Aspan. H. 2000. Running in nonconcentric circles: Why environmental management isn't being integrated into business management. Environmental Quality Management, 9/4: 9-15.

13. Lewis, H., J. Gretsakis. 2001. Design environment: A global guide to 
designing greener goods. Greenleaf Publishing.

14. K. Hansmann, K. Claudia. 2001. Green manufacturing and operations: from design to delivery and back. 192-204.

15. Fresner, J. 1998. Cleaner production as a means for effective green management, Journal of Cleaner Production, 6, 34/9, pp.171-179

16. Oliveira, O., Serra, J" Salgado, M. 2010. Does ISO 14001 work in Brazil? Journal of Cleaner Production, 18/8, pp.1797-1806.

17. Emery, F. E. and E. Trist. 1965, "The Causal Texture of Organizational Environments," Human Relations, 18, pp 21-32.

18. Porter, M., 1980. Competitive Strategy: Techniques for Analyzing Industries and Competitors, New York: The Free Press.

19. Schutzenberger, M. 1965. "A Tentative Classification of Goalseeking Behaviors," Journal of Mental Science, 100, 97-102 as reported in Emery, F. and Trist, E. 1965. "The Causal Texture of Organizational Environments," Human Relations, 18, pp 21-32.

20. Metcalf, J. L. 1974. "Systems Models, Economic Models and the Causal Texture of Organizational Environments," Human Relations, 27/7, pp 639-563.

21. Grahame R. Dowling. 1983. The Application of General Systems Theory to an Analysis of Marketing Systems. Journal of Macromarketing. 23. pp $22-32$.
22. Damali, Henriques, I., Sadorsky, P. 2008. Do green management systems improve business performance? Journal of International Management, 14, 4/12, pp. 364-376

23. Steger, U. 2000. Green management systems: empirical evidence and further perspectives, European Management Journal, 18, 1/2 pp.23-37.

24. Musicki, S., Vasovic, D., Stankovic, M. 2011. Eco-efficiency and the competitivness oforganization, Proceedings, First International Conference Engineering Management and Competitiveness, pp. 117-122.

25. Petroni, A. 2001. Developing a methodology for analysis of benefits and shortcomings of a large machinery manufacturer, Journal of Cleaner Production, 9/8 2001. pp. 351-64

26. Robert, K. H. et al. 2002. Strategic sustainable development-selection, design and synergies of applied tools, Journal of Cleaner Production, 10, 3/6, pp. 197-214

27. Dodgson, M. 1993. Organizational learning: A review of some literatures, Organization Studies., 14, 3, pp.375-394.

28. Hosseini, A 2007. Identification of green management system's factors: A conceptualized model. International Journal of Management Science and Engineering Management. 2. 3, pp. 221-228 